Dicle Tıp Dergisi / Dicle MedicalJournal (2018) 45 (2) : 223-227

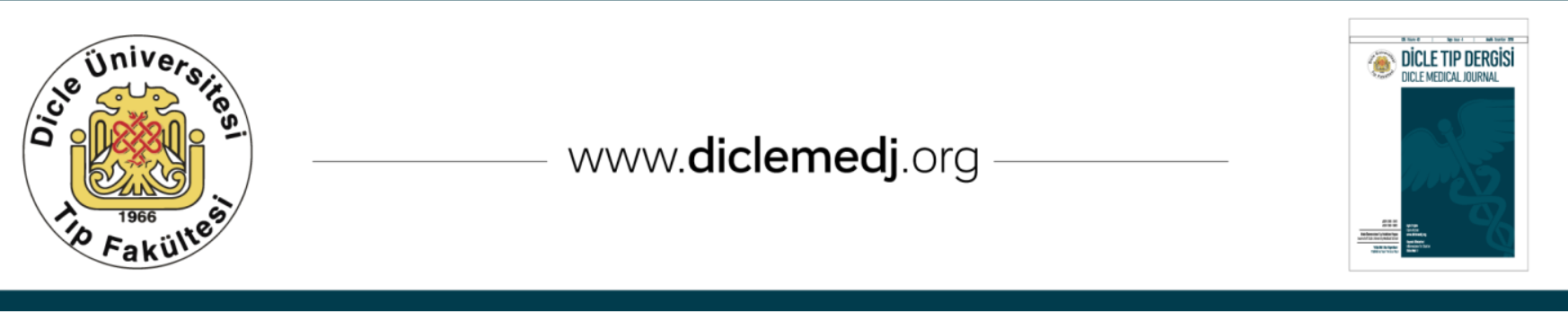

Olgu Sunumu / Case Report

\title{
Akut Solunum Sikıntısına Neden olan Travmatik Tiroid Hematomuna Multidisipliner Yaklaşım: Olgu Sunumu
}

\author{
Mert Cemal Gokgoz¹ ${ }^{\text {, Izzet Ökçesiz }}{ }^{2}$, Hamdi Taşlı ${ }^{3}$, Yusuf Çağlar Yiğit , Ahmed Taha5
}

1 Siirt Devlet Hastanesi, Kulak Burun Boğaz Kliniği, Siirt, Türkiye, ORCID: 0000-0001-8389-5601

2 Siirt Devlet Hastanesi, Radyoloji Kliniği, Siirt, Türkiye, ORCID: 0000-0002-0257-1769

3 Sanlıurfa Birecik Devlet Hastanesi, Kulak Burun Boğaz Kliniği, Sanlıurfa, Türkiye, ORCID: 0000-0003-2186-5006

4 Siirt Devlet Hastanesi, Acil Hastalıkları Kliniği, Siirt, Türkiye, ORCID: 0000-0003-0408-147x

5 Siirt Devlet Hastanesi, Genel Cerrahi Kliniği, Siirt, Türkiye, ORCID: 0000-0003-1338-7710

Öz

Tiroid bezi hematomları akut solunum sıkıntısına neden olması nedeniyle hızlı değerlendirme ve müdahale gerektiren acil bir patolojidir. Hematomun bası etkisine bağlı solunum sıkıntısı derecesi değișebilir ve müdahale kararında belirleyicidir. Boynuna aldığı darbe sonrasında akut solunum sıkıntısı gelişen 38 yaşında bilinen bir hastalığı olmayan olgumuz, fizik muayene ve radyolojik tetkikler sonrasında acil hastalıkları, kulak burun boğaz, genel cerrahi ve radyoloji uzmanı tarafından birlikte değerlendirildi. Boyun ultrasonunda (USG) tiroid sol lobda yaklaşı $6 * 4 \mathrm{~cm}$ boyutunda, sol karotiskommunis arteri yaylandıran, kistikkomponentleri ön planda heterojen ekojenitelinodüler imaj izlendi. Tanımlanan bölgeye travma öyküsü olması ve öncesinde hastanın kistiknodüler guatr öyküsü bulunmaması nedeniyle sonografik bulgular öncelikle hematom lehine değerlendirildi. Bilgisayarlı Boyun Tomografisi 'Tiroid sol lobunda 57*44 mm boyutunda hipodensnodül izlenmiş olup trakeayı sağa deviye etmektedir' şeklinde raporlandı. Tiroidhematomlarında solunum sıkıntısının derecesine göre; takip ve oksijen desteği, USG eşliğinde aspirasyon, cerrahi müdahale (hemitiroidektomi, total tiroidektomi, kanama kontrolü), entübasyon ve entübasyon yaplamazsa trakeotomiinferior tedavi seçenekleri arasındadır. Biz bu olguda oldukça nadir gözüken travmatiktiroidhematomundaultrason eşliğinde yapılan aspirasyon yöntemi ile tedavi yaklaşımımızı sunduk.

Anahtar kelimeler: Tiroid, Hematom, Ultrason.

DOI: $10.5798 /$ dicletip. 410843

Yazışma Adresi / Correspondence: Mert Cemal Gokgoz, Siirt Devlet Hastanesi, Kulak Burun Boğaz Kliniği, Siirt, posta kodu:56100, Türkiye, e-mail: drmcgokgoz@gmail.com 


\title{
Multidisciplinary Approach to Traumatic Thyroid Hematoma Causing Acute Respiratory Distress: A Case Report
}

\begin{abstract}
Thyroid gland hematoma is an urgent pathology that requiring rapid evaluation and intervention because of acute respiratory distress. The degree of respiratory distress due to hematoma pressure effect can change and is determinative in the intervention decision. A 38-year-old patient with acute respiratory distress after blunt trauma to his neck, were evaluated with emergency diseases, otorhinolaryngology, general surgery and radiology specialist after physical examination and radiological examinations. Neck ultrasonography showed that approximately $6 * 4 \mathrm{~cm}$ size, including a cystic component, heterogeneous echogenic nodular image on the left thyroid lobe. Sonographic findings were evaluated primarily for hematoma. Neck CT is reported as 'hypodense nodule is with a size of $57 * 44$ mm in the left lobe of thyroid and the trachea is deviated to the right'. According to the degree of respiratory distress in thyroid hematomas, there are different treatment options as follow up and oxygen support, needle aspiration with USG, surgical intervention (hemithyroidectomy, total thyroidectomy, hemorrhage control), intubation and tracheotomy inferior. In this case, we presented our treatment approach with USG-guided needle aspiration in traumatic thyroid hematoma.
\end{abstract}

Keywords: Thyroid, Hematoma, Ultrasonography.

\section{GíRiş}

Tiroid bezi kaynaklı hematomlar akut solunum sıkıntısına neden olması ve hızlı müdahale gerektirmesi nedeniyle önemlidir. Cerrahi sonrası gelişebileceği gibi travmatik ve nontravmatik nedenler ile oluşabilir. Hematomun bası etkisine bağlı solunum sıkıntısı derecesi değișebilir ve müdahale kararında belirleyicidir. Biz, bu olgu sunumunda boynuna aldığı darbe sonrasında tiroidhematomu nedeniyle akut solunum sıkıntısı gelişen hastadaki yaklaşımımızı sunduk.

\section{OLGU}

38 yaşında erkek hasta, halı saha maçı sırasında boynuna aldığı darbe sonrasında dakikalar içerisinde boynunun sol yanında şişlik oluştuğunu ve beraberinde solunum sıkıntısı gelişmesi üzerine Siirt Baykan Devlet Hastanesi Acil servisine başvurduğunu ifade ediyor. Daha önce tiroid bezi hastalıklarına yönelik öyküsü bulunmayan hasta, ilk değerlendirme sonrasında çekilen Bilgisayarlı Boyun
Tomografisinde "Tiroidsol lobunda $57 * 44 \mathrm{~mm}$ boyutunda hipodensnodül izlenmiş olup trakeayı sağa deviye etmektedir' şeklinde raporlanması üzerine Siirt Devlet Hastanesi Acil servisine sevk edildi. Boyun travmasinın bir saat sonrasında acil serviste yapılan ilk değerlendirme de vital bulgular TA: 130/80 $\mathrm{mm} / \mathrm{Hg}$, nabız:92 atım/dk, ateş: 37.50C ve 02 saturasyonu: \%95 olarak belirlendi. Solunum sayısı 22/dk idi. Solunum sıkıntısı devam eden hasta mevcut sıkıntının son 1 saattir aynı şiddette olduğunu ifade etmekteydi. Hastanın fizik muayenesindeinspeksiyonda boyun sol yanında level 4 seviyesinde şişlik izlendi. Orofarenks muayenesi tabii izlenen hastanın endoskopik muayenesinde vokal kordlar orta hatta ve hareketleri tabii idi, subglottik $1 . \mathrm{cm}$ e kadar trakeada bası izlenmedi. Palpasyonda boyun sol yanında izlenen şişliğin $5 * 5 \mathrm{~cm}$ ebatında sert ve fikse olduğu görüldü. Hastaya acil serviste oksijen desteği(4lt/dk) ve soğuk uygulama başlandı. Hastanın tam kan, rutin biyokimyasal ve tiroid fonksiyon testleri çalışıldı. Wbc:7.10, Hgb: 15.9g/dl, Plt: 238, Serbest T3: 3.03pg/ml, Serbest T4: $0.89 \mathrm{ng} / \mathrm{dl}$ 
ve TSH: $0.48 \mathrm{uIU} / \mathrm{ml}$ olarak sonuçland. Pıhtılaşma markerlarına bakıldığında INR: 0.99, PTZ:12.8 ve Fibrinojen: 169 olarak sonuçlandı. Yapılan Boyun USG'detiroid sol lobda yaklaşık 6*4 cm boyutunda, sol karotiskommunis arteri yaylandıran, kistikkomponentleri ön planda heterojen ekojenitelinodüler imaj izlendi. Tanımlanan bölgeye travma öyküsü olması ve öncesinde hastanın kistiknodüler guatr öyküsü bulunmaması nedeniyle sonografik bulgular öncelikle hematom lehine değerlendirildi. Kulak Burun Boğaz, Radyoloji, Acil ve Genel Cerrahi uzmanının yaptığı ortak değerlendirme sonucunda hastaya ilk olarak USG eşliğinde aspirasyon yapılmasına karar verildi. Hastaya USG eşliğinde Radyoloji uzmanı tarafından yapılan aspirasyonda yaklaşık 10 cc hemorajik mayi aspire edildi. Aspirasyon sonrasinda solunum sıkıntısı azalan hasta, acil serviste yakın gözlem altında tutuldu. 8 saat sonrasında yapılan kontrol USG delezyon boyutlarında anlaml farklılı saptanmazken, ekojenkomponentin azaldığı ve hemorajik materyali temsil ettiği düşünülen anekoikkomponentin arttığının tespit edilmesi üzerine, USG eşliğinde aspirasyonun yinelenmesine karar verilerek, tekrar yapılan aspirasyonda 20 cc hemorajik mayi aspire edildi. Hasta aspirasyon sonrasinda solunum açısından belirgin olarakrahatladığını ifade etti. Yakın takibe devam edilen hasta 3. günde taburcu edildi.

\section{TARTIŞMA}

Tiroid bezi içerisinde bilinen yada bilinmeyen nodül/kist varlığında travmatik olarak trafik kazaları, spor yaralanmaları ve boyun bölgesine alınan künt darbeler ile non-travmatik olarak koagülasyon bozuklukları ve antikoagülan kullanımı ile nodül/kist içerisine kanama meydana gelebilmektedir ${ }^{1-3}$. Adenomatöztiroid nodüllerinin vaskülaritesinin fazla olması travma sonrasında hematom gelişme ihtimalini artırmaktadır. Biz bu olguda tiroid bezi içerisinde nodül varlığından haberi olmayan yetişkin bir hastada boyun bölgesine gelen travma sonrasında dakikalar içerisinde gelişen tiroidhematomu ve buna bağlı solunum sıkıntısına yaklaşımımızı sunduk. Tiroid bezi hematomları akut solunum sıkıntısına neden olması nedeniyle hızl değerlendirme ve müdahale gerektirmektedir ${ }^{3}$. Solunum sıkıntısının derecesine göre; takip ve oksijen desteği, USG eşliğinde aspirasyon, cerrahi müdahale (hemitiroidektomi, total tiroidektomi, kanama kontrolü), entübasyon ve entübasyon yapılamazsa trakeotomiinferior tedavi seçenekleri arasındadır. Aynı zamanda solunum sıkıntısına neden olan durumun tiroid bezi kaynaklı mi, yoksa boyundaki arteryel/venöz yapılardan kaynaklı mı olduğunun ayırt edilmesi yaklaşım açısından önemlidir. Boyuna alınan darbe sonrasında gelişen solunum sıkınıtısındalateral boyun grafileri, ultrason ve bilgisayarlı tomografi tanıda yardımcıdır. Lateralgrafiler özellikle prevertebral ve retrofarengeal bölgenin değerlendirilmesi açısından fikir vermektedir. Bizim hastamı hastanemize boyun BT'si çekilmiş şekilde başvurmuş ve akabinde hemen yatakbaşıUSG'si çekilmiştir. BT, derin dokularda hematomun uzanımı, trakea ve larinks hakkında detaylı bilgi vermektedir. USG, akut süreçte hızlı uygulanabilmesi, iyonizan radyasyon içermemesi ve kolay uygulanabilir olması nedeniyle kullanılabilir. Ayrıca, bizim vakamızda da olduğu gibi, girişimsel radyolojik işlemlere kılavuzluk edebilmektedir. İleri değerlendirme ise ciddi vasküler yaralanma şüphesinde Doppler US veya BT anjiografi tercih edilmelidir.

Hastaların ilk başvuru anında solunum sıkıntısı hafif seviyede olabilir ve bası semptomları artıkça solunum sıkıntısı artabilir. Bizim hastamız son 1 saattir solunum sıkıntısının aynı şekilde olduğunu ve mevcut durumu rahatlıkla tolere edebildiğini ifade etmiştir. Solunum sıkıntısının artabileceği düşünülerek hastalar yakın takip altında tutulmalıdır. Travmatikhematomlara yaklaşım konusunda ortak görüş bildiren bir rehber olmamasından 
dolayı solunum sıkıntısı olan hastanın cerrahi öncesi ilk basamak tedavisinde minimal invaziv bir yöntem olan USG eşliğinde aspirasyon düşünülmüştür. İğne ile aspirasyon açısından zorluk oluşturan nokta, hematom içeriğinin pıhtılaşma sonucunda yoğun bir hal almasıdır. Bizim hastamızda nodül içerisine kanama olduğunu düşündügümüzden dolayı ilk aspirasyon sırasinda gelen kana göre daha kıvamlı olan 10 cc'likhemorajik koyu renkli materyal yeterli görülüp hastanın durumunun stabil olması nedeniyle takipte kalınmıștır. Hastaya 8 saat sonra yapilan kontrol USG'sindenodülün içerisindeki heterojen alanın kısmen küçüldüğü ve hematom imajı veren alanın daha büyüdüğü görülmüştür. İkinci sefer yapılan aspirasyonda 20 cc hemorajik koyu kırmızı renkli materyal aspire edilmiștir ve aspirasyon sonrasinda hasta belirgin hissedilir düzeyde rahatladığını ifade etmiştir. Her iki iğne aspirasyonunun 10 dakika sonrasında aspirasyona bağlı hemoraji oluşup oluşmadığı USG ile kontrol edilmiştir ${ }^{4}$. Hematomun sınırlandırılması açısından boyun baskılı sarılması yapılabilmekle beraber bizim hastamızın stabil durumu ve solunum sıkıntısının derecesi nedeniyle tercih edilmemiştir.

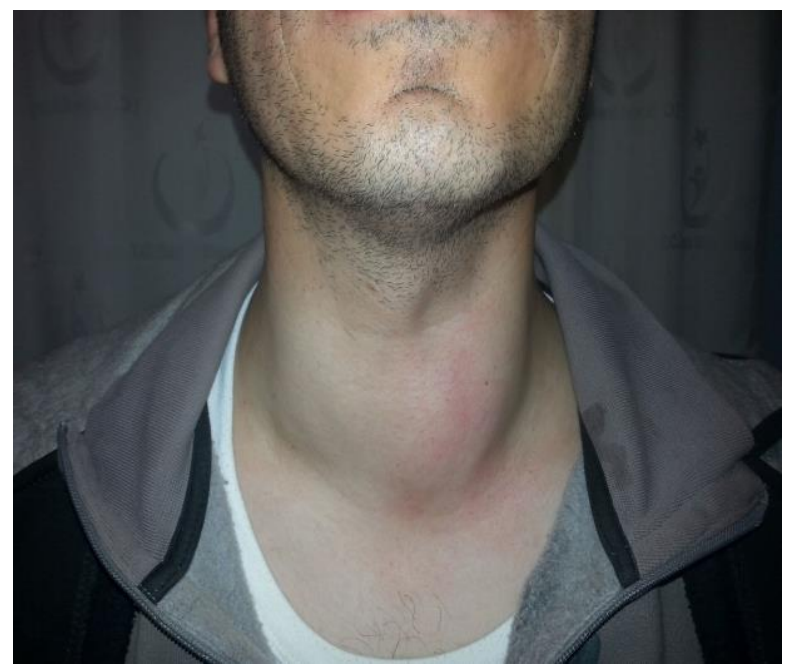

Şekil 1: Hastanın Boyun Görüntüsü

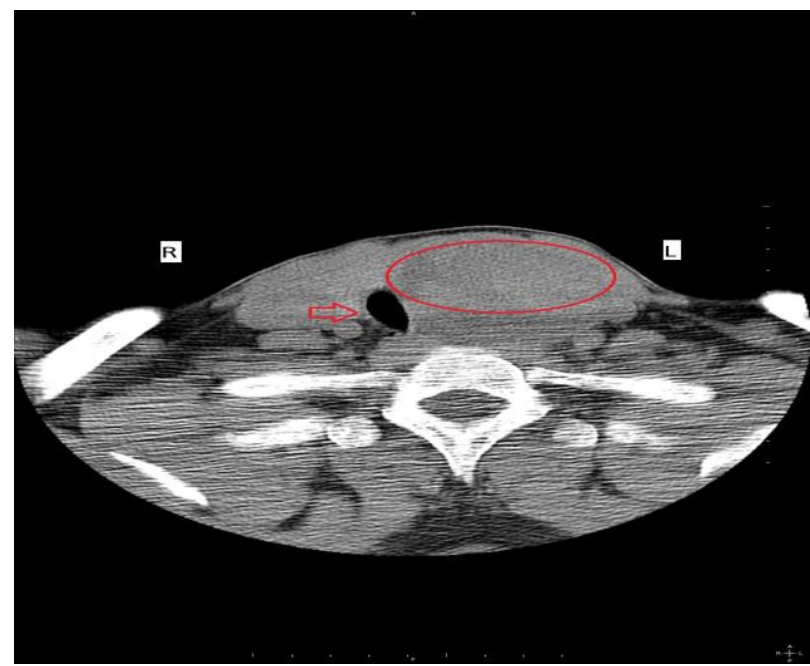

Şekil 2: BT de Trakeanın Sağa Doğru Deviye olduğu Nodül İmajı (Ok: Trakea, Oval şekil: Nodül içine kanama / hematom)

Aspirasyon sonrası rahatlamayan hastalarda ve solunum sıkıntısı ile disfajinin ciddi seviyede olduğu hastalarada acil olarak nodülün yerleşimine göre hemitiroidektomi ve ya tiroidektomi düşünülebilir ${ }^{5}$. Sadece hematomun boşaltılması ise tiroidektomi sonrası gelişen hematomlarda ve tiroid dışı hematomlarda düşünülmelidir.

Travmatik tiroid hematomunda havayolu yönetiminde, tedavi kararı verilirken hastanın solunum sıkıntısının derecesi belirgin rol oynamaktadır. Radyolojik olarak grafi, USG ve BT yaklaşımda belirleyici rol oynayan diğer faktörlerdir. Cerrahi öncesinde hastanın durumu stabil ise USG eşliğinde iğne aspirasyonu cerrahiye göre non-invaziv ve hastanın şikayetlerini rahatlatıcı bir seçenektir.

Çıkar Çatışması Beyanı: Yazarlar çıar çatışması olmadığını bildirmişlerdir.

Finansal Destek: Bu çalıșma her hangi bir fon tarafından desteklenmemiștir.

Declaration of Conflicting Interests: The authors declare that they have no conflict of interest.

Financial Disclosure: No financial support was received. 


\section{KAYNAKLAR}

1. Best CA, Dhaliwal S, Tam S, et al. Spontaneous intrathyroidal hematoma causing airway obstruction: A case report. Medicine (Baltimore). 2016; 95:35-9.

2. Chartier LB, Turner JP. Delayed intrathyroidal hematoma causing respiratory distress after a seemingly benign fall: a case report. Int J Emerg Med. 2010; 8;3:431-3.

3. Tsilchorozidou T, Vagropoulos I, Karagianidou C, Grigoriadis N. Huge intrathyroidal hematoma causing airway obstruction: a multidisciplinary challenge. Thyroid. 2006; 16:795-9.
4. Roh JL. Intrathyroid hemorrhage and acute upper airway obstruction after fine needle aspiration of the thyroid gland. Laryngoscope. 2006; 116:154-6.

5. Marta Pérez NM, Enjuto D, Molero SS, et al. Cervical hematoma secondary to spontaneous rupture of a thyroidnodule. JSM Clin Case Rep 2015; 2:1064. 